\title{
Computational investigation on heat transfer augmentation of a circular tube with novel hybrid ribs
}

\author{
Suvanjan Bhattacharyya ${ }^{1, *}$, Devendra Kumar Vishwakarma ${ }^{1}$, Sanghati Roy $^{1}$, Kunal Dey ${ }^{2}$, Ali Cemal Benim ${ }^{3}$, Rachid \\ Bennacer ${ }^{4}$, Akshoy Ranjan Paul ${ }^{5}$, and Z. Huan ${ }^{6}$ \\ ${ }^{1}$ Department of Mechanical Engineering, Birla Institute of Technology and Science, Pilani, Pilani Campus, Vidya Vihar, Rajasthan \\ 333031, India \\ ${ }^{2}$ Department of Mechanical Engineering, National Institute of Technology Agartala, Tripura, India \\ ${ }^{3}$ Center of Flow Simulation (CFS), Duesseldorf University of Applied Sciences, Germany \\ ${ }^{4}$ Université Paris Saclay, 61 avenue du Président Wilson, 94230 Cachan, France \\ ${ }^{5}$ Department of Applied Mechanics, Motilal Nehru National Institute of Technology Allahabad, Prayagraj, UP, India \\ ${ }^{6}$ Department of Mechanical Engineering, Mechatronics and Industrial Design, Tshwane University of Technology, Private Bag \\ X860, Pretoria 0001, South Africa
}

\begin{abstract}
Present study reports a computational investigation on heat transfer and pressure drop characteristics for flow through a heat exchanger tube fitted with novel hybrid ribs by using magnetic nanofluid $\left(\mathrm{Fe}_{3} \mathrm{O}_{4}\right)$. Effects of different rib geometry on heat transfer and pressure drop characteristics have been investigated for Reynolds number ranging from 3000 to 22000 . Until now, there is little information available in the literature on the method of quantifying the effect of forced convection on the heat transfer and pressure drop of hybrid rib (HR) inserts by using magnetic nanofluid (MNF). The transition SST models along with governing equations (continuity, momentum, and energy equations) are numerically solved with ANSYS Fluent 19.2. The simulation results are validated with established correlations and excellent agreement was found. Heat transfer coefficient is more in combined arrangement (HR and MNF) compared to acting alone arrangement (only MNF).
\end{abstract}

\footnotetext{
* Corresponding author: suvanjan.bhattacharyya@pilani.bits-pilani.ac.in
} 


\section{Introduction}

Heat exchangers are essential devices for the heat transfer. They found application in power generation, chemical, bio-medical, refrigeration and air conditioning, automobile, aerospace industries, etc [1]. The performance of heat exchanger is determined on the basis of heat transfer coefficient and pressure drop [2-4]. It is always essential for a heat exchanger to give higher heat transfer coefficient while keeping the pressure drop low [5-8]. Several enhancement methods are developed to increase the thermal and flow performance of heat exchangers. These modifications include swirl generators such as twisted tapes [9-16], artificial roughness in the form of corrugation [14] and ribs on the surface of duct [17], usage of fins and baffles [18], nanofluids [19-21], etc. Such modifications introduce the interference in the flow field which result in disturbed boundary layer, mixing of fluid elements as a result of which heat transfer is enhance.

Among various heat transfer enhancement techniques, usage of ribs is very effective in term of economy while keeping the thermal performance higher. Ribs act as the turbulence promoter which allows the disturbance in the flow field as a result of which secondary flow is promoted and heat transfer rate is enhanced. Investigators are studying the various geometrical aspect of ribs in order to optimize the heat transfer rate and pressure drop. Karwa et al. [22] investigated the thermo-hydraulics of fluid flow in one sided rib-roughened rectangular duct with uniform heating in transitional flow regime with air was taken as the working fluid and developed correlations for predicting the heat transfer and friction factor. Zhang [23] numerically revealed the heat transfer and pressure drop in the cross-corrugated triangular channel in transitional flow regime and developed correlations for heat flux with uniform temperature and uniform heat flux condition. Chang and Jian [24] investigated the thermal and flow performance by employing the ribs along with auxiliary fins and reported that the compound technique of heat transfer enhancement improve the thermal performances of turbulent channel flow. Jain et al. [25] reported on the arc-shaped ribs with multiple gaps for thermal and flow characteristics enhancement of a solar air heater. The Reynolds number is varied from 3000 to 18000 and arc angle varied from $30^{\circ}$ to $75^{\circ}$. Influence of Reynolds number on the heat transfer as well as friction factor was noted and the maximum enhancement in heat transfer was reported at arc angle of $60^{\circ}$ for all values of Reynolds number. Saha [26] conducted experimental assessment to investigate the influence of transverse ribs and wire coil insert on the thermo-hydraulics of turbulent flow inside a rectangular and square channel. It was found that the combination of transverse ribs along with wire coil insert performs better when both were acting alone. Bhattacharyya et al. [27] performed CFD based evaluation to report on the thermal and flow characteristics inside a circular channel employed with alternating transverse ribs for all the flow regimes. For
Reynolds numbers between 500 and 5 000, a notable increase in thermal performance is anticipated. Kumar et al. [28] conduct numerical and experimental study to investigate on the thermal and flow characteristics when employed with dimpled ribs. The simulation results show a 3.18-fold increase in heat transfer and a 2.87-fold increase in thermal hydraulic performance. Du and Hong [29] conducted experimental evaluation to report on the thermal and flow characteristic of ribbed heat exchanger duct fitted with regular spaced helical tape. Considerable enhancement in heat transfer and friction factor was reported.

Recently, the usage of nanofluids along with other passive heat transfer enhancement method is very much appreciated due to encouraging results. Several research works are going to investigate more on the usage of nanofluid in order to increase its commercialization. In the previous decade, the usage of magnetic nanofluid for the heat transfer enhancement showed a gradual increment due to its higher thermal conductivity as compared to other nanofluids. Gui et al. [30] reported on the influence of external magnetic field on the heat transfer rate of ferrofluid and found that increase in volume fraction increase the heat transfer while the increase in magnetic field intensity showed adverse effect due to decrease in the bulk fluid thermal conductivity. Qi et al. [31] conducted experimental assessment for thermal transfer, exergy efficiency, and entropy generation for CPU cooling using magnetic nanofluid and reported decrease in the CPU surface temperature with increase in magnetic intensity. Aghabozorg et al. [32] investigated the thermal performance of shell and tube heat exchanger with employment of $\mathrm{Fe}_{2} \mathrm{O}_{3}-\mathrm{CNT}$ magnetic nanoparticles and revealed that the convective heat transfer coefficient increases as the weight concentration and temperature increase.

Recently, compound or combinational techniques of heat transfer enhancement are proving their momentum due to higher heat transfer performance. In combinational techniques of heat transfer enhancement use of two different heat transfer enhancement techniques (Active-passive, Passive-passive, Activeactive) are combined in order to enhance the heat transfer performance [33-36]. Safaei et al. [37] performed simulation study to investigate the influence of water/functionalized multi-walled carbon nanotube (FMWCNT) nanofluid along with forward-facing step on the thermal and flow performance in turbulent flow regime and reported on the hydraulics and thermal behavior of nanofluid flow as a function of nanoparticle concentration, shear energy, heat flux, contraction, and turbulence. Navaei et al. [38] carried out a numerical investigation to evaluate the thermohydraulics inside a rib-grooved channels under uniform heat flux and various nanofluids flowing through it. The result obtained from the investigation shows enhancement in heat transfer with increase in the volume fraction while decrease in heat transfer is noticed with increase in the particle size. Salman et al. [39] used ANSYS FLUENT to investigate the effects of two-dimensional turbulent nanofluids flow in 
various ribs tube structures on heat transfer, friction, and coefficients of thermal transport.

It is clearly noted from the above literature reviewed, that the simultaneous use of nanofluids with different ribs tube configuration was utilized as the most efficient technique for further enhancement of heat transfer rate as compared with the individual uses of ribs or nanofluid.

The main objective of the present research is to investigate the combined effects of magnetic nanofluid with different volume fractions in a constant heat flux circular tube with hybrid rib inserts. Till date no work has been reported on hybrid ribs with magnetic nanofluid.

\section{Analysis and modelling}

The computational domain is shown in Figure 1 is designed and developed in the Ansys DesignModeler software application of ANSYS 19.2. The Reynolds number of the magnetic nanofluid are varied from 3000 to 22000 . The tube length is $2000 \mathrm{~mm}$ and tube diameter is $20 \mathrm{~mm}$. Three different pitch ratios (y) are tested $\mathrm{y}=5.0,10.0$ and 15.0. The transition shear stress transport (SST) model of Menter et al. [40] is utilized to accurately forecast separation by catching mixing behaviour. Uniform inlet velocity condition is applied while no slip condition is assumed at all the solid surfaces. $5 \%$ of turbulent intensity at the inlet is given to the fluid. Grid independence study with enough numbers of cells has been achieved to generate meshing around hybrid ribs as shown in Figure 2.

The basic governing equations used for the analysis are provided below $[40,41]$. Note that the variables are meant as time-averaged ones (Nomenclature: $u_{i}, v$ : velocity vector, $p$ : pressure, $T$ : temperature, $\kappa$ : turbulence kinetic energy, $\omega$ : specific dissipation rate, $C_{p}$ : specific isobaric heat capacity, $\mu$ : molecular viscosity, $k$ : molecular thermal conductivity, $\mu_{\text {turb }}$ : turbulent viscosity)

Conservation of Mass

$$
\nabla .(\rho v)=0
$$

Conservation of Momentum

$$
\nabla \cdot(\rho v v)=-\nabla p+\nabla \cdot\left(\left(\mu+\mu_{t u r b}\right) \nabla v\right)
$$

Conservation of Energy

$$
\nabla \cdot\left(\rho v C_{p} T\right)=\nabla \cdot\left(\left(k+\frac{\mu_{t u r b}}{\sigma_{T} / C_{p}}\right) \nabla T\right)
$$

Equations of the turbulence model

$$
\begin{aligned}
\frac{\partial\left(\rho u_{i} \kappa\right)}{\partial x_{i}}=\gamma \cdot P_{\kappa} & -\beta_{1} \rho \kappa \omega \\
& +\frac{\partial}{\partial x_{i}}\left(\left(\mu+\frac{\mu_{\text {turb }}}{\sigma_{\kappa}}\right) \frac{\partial \kappa}{\partial x_{i}}\right) \\
\frac{\partial\left(\rho u_{i} \omega\right)}{\partial x_{i}}=A \rho S^{2}- & \beta_{2} \rho \omega^{2} \\
& +\frac{\partial}{\partial x_{i}}\left(\left(\mu+\frac{\mu_{\text {turb }}}{\sigma_{\omega}}\right) \frac{\partial \omega}{\partial x_{i}}\right) \\
& +2\left(1-F_{1}\right) \rho \frac{1}{\sigma_{\omega 2} \omega} \frac{\partial \kappa}{\partial x_{i}} \frac{\partial \omega}{\partial x_{i}}
\end{aligned}
$$

with

$$
\mu_{t u r b}=\rho \frac{k}{\omega} \frac{1}{f\left(R e_{t}, \omega, S, F_{2}\right)}
$$

where $a, A, \beta_{i}, \sigma_{i}$ are model constant, $S$ is time average strain rate, $\mathrm{F}_{\mathrm{i}}$ are blending functions, $P_{i}$ and $E_{i}$ represent production and destruction terms.

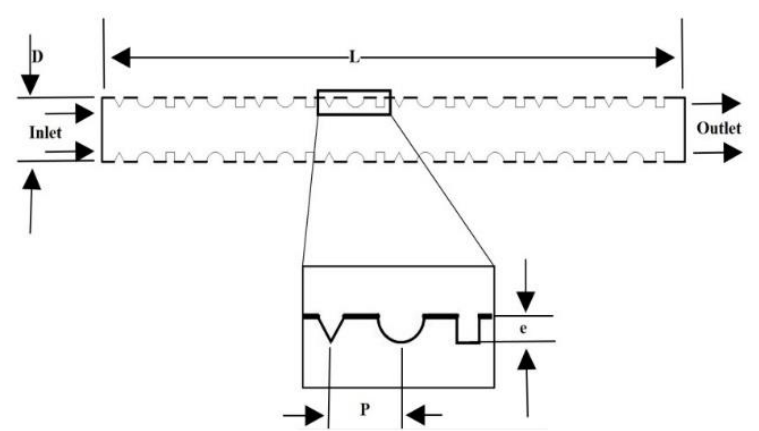

Fig. 1. Computational domain : Hybrid ribs

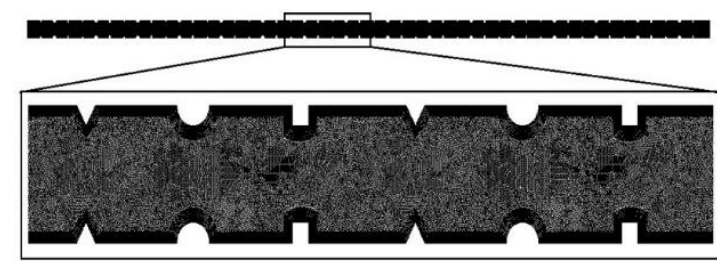

Fig. 2. Meshing of the computational domain

\section{Thermophysical magnetic nanofluid \\ properties of}

For estimating the effective thermal conductivity of nanofluid, Wasp [42] theoretical correlation is used in the present study, and it is described as follows, where $\varphi$ denotes the nanoparticle volume fraction:

$$
\begin{aligned}
& k_{\text {nanofluid }} \\
& =k_{\text {water }}\left\{\frac{k_{\mathrm{Fe}_{3} \mathrm{O}_{4}}+2 k_{\text {water }}-2 \phi\left(k_{\text {water }}-k_{\mathrm{Fe}_{3} \mathrm{O}_{4}}\right)}{k_{\mathrm{Fe}_{3} \mathrm{O}_{4}}+2 k_{\text {water }}+2 k_{\mathrm{Fe}_{3} \mathrm{O}_{4}}\left(k_{\text {water }}-k_{\mathrm{Fe}_{3} \mathrm{O}_{4}}\right)}\right\}
\end{aligned}
$$

For estimating effective dynamic viscosity of nanofluid, Brickman [43] model is considered which is given as: 


$$
\mu_{\text {nanofuid }}=\mu_{\text {water }}\left(\frac{1}{(1+\varphi)^{2.5}}\right)
$$

Density and specific heat of nanofluid are calculated by the correlation of Pak and Cho [44-45]:

$$
\begin{aligned}
& \rho_{\text {nanofuid }}=(1-\varphi) \rho_{\text {water }}+\varphi \rho_{\mathrm{Fe}_{3} \mathrm{O}_{4}} \\
& \mathrm{C}_{\text {nanofuid }}=(1-\varphi) \mathrm{C}_{\text {water }}+\varphi C_{\mathrm{Fe}_{3} \mathrm{O}_{4}}
\end{aligned}
$$

\section{Results and Discussion}

Figure 3 shows the good agreement between Nusselt number $(\mathrm{Nu})$ values obtained from the simulations and Notter-Rouse [46] under tested flow condition.

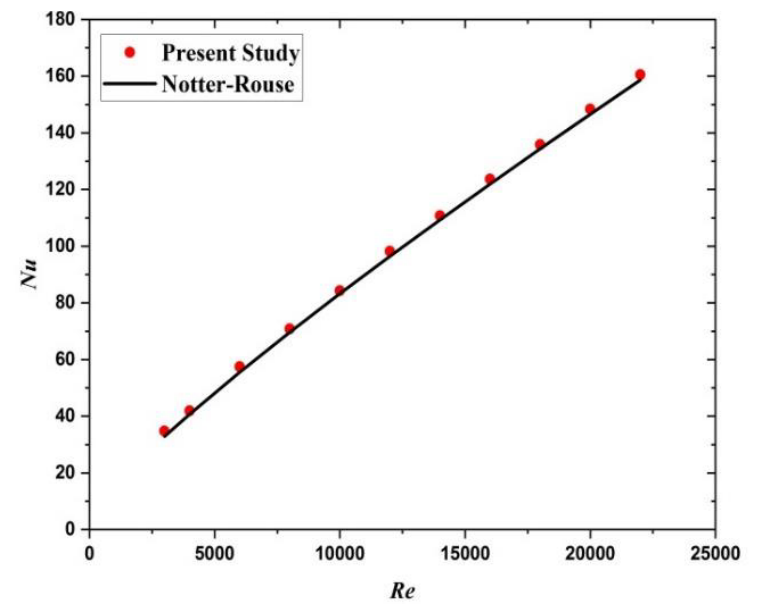

Fig. 3. Validation : Nusselt Number

Fig. 4 shows the Nusselt number for $\mathrm{Fe}_{3} \mathrm{O}_{4}$-water magnetic nanofluid flowing through plain tube, compared with the results of water. Increase in convective heat transfer is noticed with increase in Reynolds number ( $\mathrm{Re}$ ) and volume fraction. At volume fraction of $0.6 \%, 24.77 \%$ of heat transfer enhancement is noticed at Reynolds number of 3000 while at 22000 , this enhancement is increased by $34.25 \%$. This is due to the higher thermal conductivity of the working fluid due to evenly dispersion of nanoparticles in the base fluid.

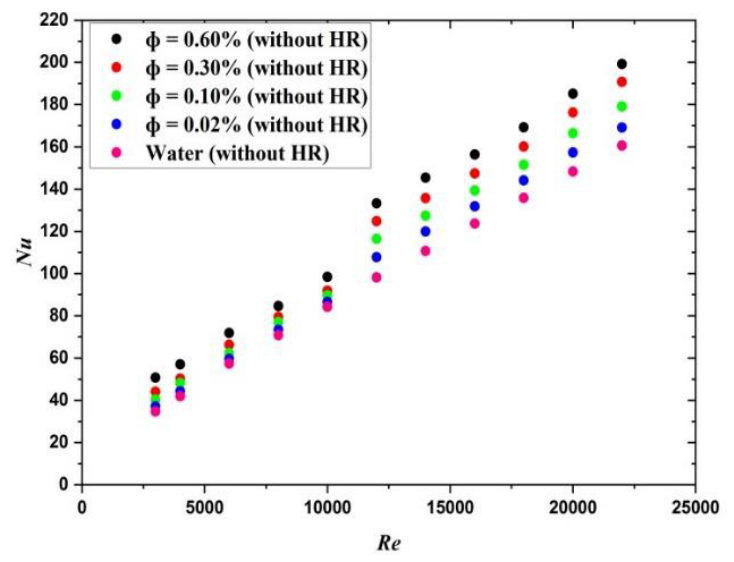

Fig. 4. $\mathrm{Nu}$ as the function of Re for water and different volume concentration magnetic nanofluid

In Figure 5, the Nusselt number of various volume concentrations of $\mathrm{Fe}_{3} \mathrm{O}_{4}$ nanofluid in circular tube with hybrid ribs, as well as water, are presented. As compared to MNF in a plain tube, MNF with hybrid ribs achieves higher heat transfer rates. The ribs induce turbulence within the flow field, which allows for efficient fluid mixing. For $0.6 \%$ volume fraction of nanofluid flowing in a tube with HR insert of $y=5$, $19 \%$ of heat transfer enhancement is noticed at Reynolds number of 3000 while $22 \%$ of enhancement is noticed at $\mathrm{Re}=22000$.

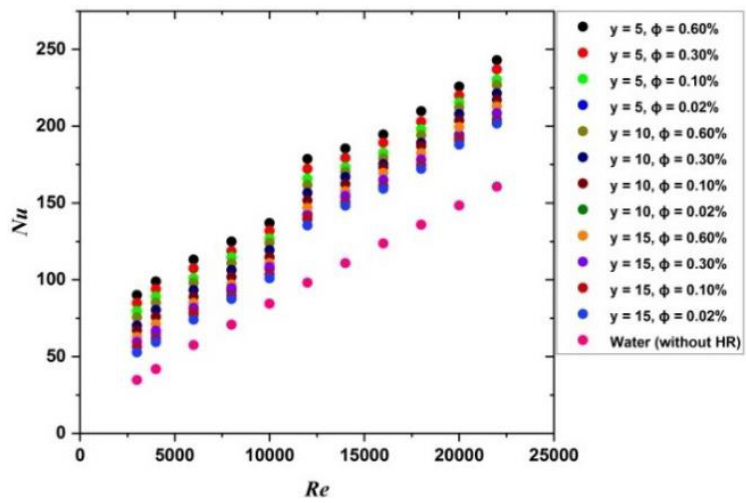

Fig. 5. $\mathrm{Nu}$ as the function of $\mathrm{Re}$ for different volume concentration magnetic nanofluid and pitch ratios

Figure 6 shows the close agreement with Blasius correlation [47] for friction factor (f). Figure 7 shows the comparison of the friction factor of $\mathrm{Fe}_{3} \mathrm{O}_{4}$-water nanofluid and pure water. A very slight increase in friction factor is noticed due the presence of solid nanoparticles which increase the viscosity of nanofluid as a result of which friction factor increases.

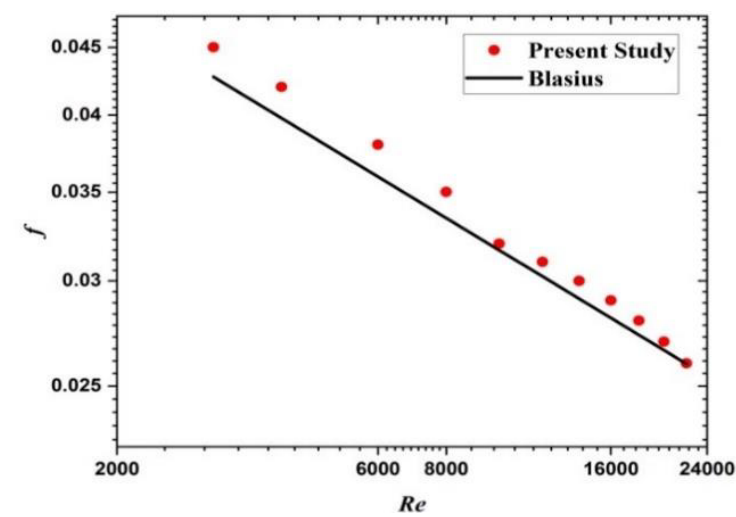

Fig. 6. Validation: Friction factor.

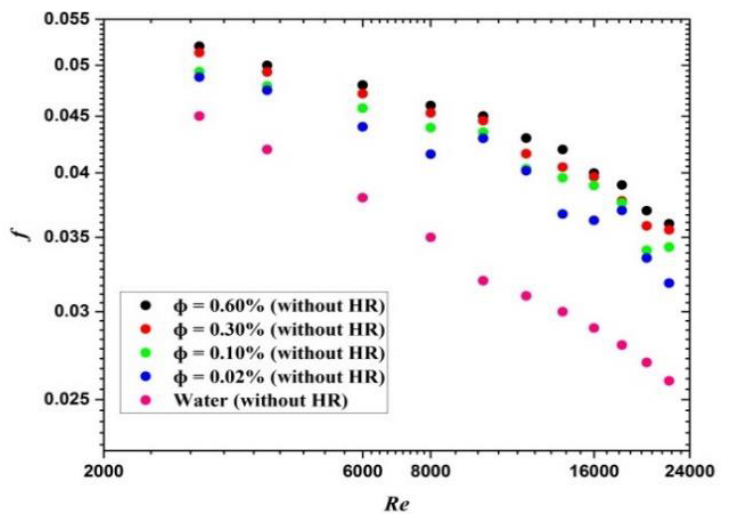

Fig. 7. Friction factor as the function of Re for water and different volume concentration magnetic nanofluid 
Figure 8 shows the comparison chart of the friction factor of different volume fraction of nanoparticles inside a ribbed duct. Increased in the friction factor is observed with insertion of hybrid ribs. As expected, the friction factor increase as the pitch ratio and volume concentration increases, but the increase is not that significant as compared to heat transfer.

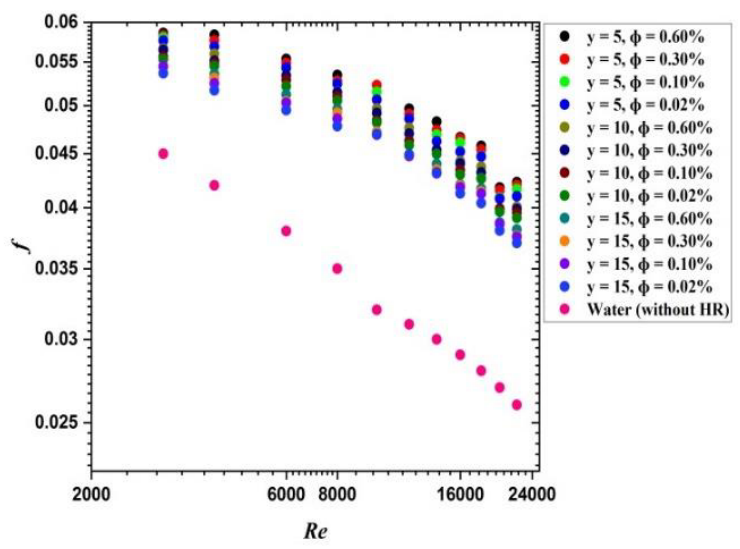

Fig. 8. Friction factor as the function of Re for different volume concentration magnetic nanofluid and pitch ratios.

\section{Conclusions}

The study reports a CFD analysis on heat transfer and friction factor characteristics for flow through a circular tube fitted with novel hybrid ribs by using magnetic nanofluid $\left(\mathrm{Fe}_{3} \mathrm{O}_{4}\right)$.

The simulation results are validated with established correlations and decent agreement was found. Increase in convective heat transfer is noticed with increase in Reynolds number ( $\mathrm{Re}$ ) and volume fraction. At volume fraction of $0.6 \%$ (without HR), $24.77 \%$ of heat transfer enhancement is noticed at Reynolds number of 3000 while at 22000 Reynolds number this enhancement is increased by $34.25 \%$. For $0.6 \%$ volume fraction of nanofluid flowing in a tube with HR insert of $\mathrm{y}=5,19 \%$ of heat transfer enhancement is noticed at Reynolds number of 3000 while $22 \%$ of enhancement is noticed at 22000 Reynolds number. This investigated outcome can be used to design efficient solar thermal system and heat exchangers.

The authors gratefully acknowledge the International cooperation division and India - South Africa Bilateral Cooperation Scheme (DST/IBCD/SA/2021/5) for the financial support.

\section{References}

1. A. Karimi, M. Afrand, Energy Convers. Manag., 164, 615 (2018)

2. S. Bhattacharyya, Iran. J. Sci. Technol. - Trans. Mech. Eng., 44, 217 (2020)

3. S. Bhattacharyya, H. Chattopadhyay, A. Haldar, Beni-Suef Univ. J. Basic Appl. Sci., 7, 118 (2018)
4. S. Bhattacharyya, A. C. Benim, R. Bennacer, K. Dey, Heat Transfer Engineering (2021) doi: 10.1080/01457632.2021.1875168

5. M. Everts, J. P. Meyer, Int. J. Heat Mass Transf., 117, 1231 (2018)

6. S. Bhattacharyya, A. C. Benim, M. Pathak, S. Chamoli, A. Gupta, J. Therm. Anal. Calorim., 140, $1519(2020)$

7. S. Bhattacharyya, J. Therm. Anal. Calorim., 140, 1355 (2020)

8. S. Bhattacharyya, S. K. Saha, Exp. Therm. Fluid Sci., 42, 154 (2012)

9. S. Bhattacharyya, A. C. Benim, H. Chattopadhyay, A. Banerjee, Exp. Heat Transf., 32, 411 (2019)

10. S. Bhattacharyya, H. Chattopadhyay, S. Bandyopadhyay, Int. J. Heat Technol., 34, 401 (2016)

11. S. Bhattacharyya, D. Sarkar, U. S. Mahabaleshwar, M. K. Soni, M. Mohanraj, Eur. Phys. J. Appl. Phys., 92, 3091 (2020)

12. S. Bhattacharyya, H. Chattopadhyay, S. Bandopathyay., S. Roy, A. Pal, S. Bhattacharjee, Int J. Heat Technol., 34, 191 (2016)

13. S. Bhattacharyya, H. Chattopadhyay, in Proc. CHT-15, $6^{\text {th }}$ Int. Symp. Adv. Comput. Heat Transf., May 25-29, 2015, Rutgers Univ. New Brunswick, NJ, USA (Begell House, Connecticut, 2015), p. 12

14. S. Rainieri, F. Bozzoli, and G. Pagliarini, Int. J. Heat Mass Transf., 55, 498 (2012)

15. M. El Ganaoui, M. El Jouad, R. Bennacer, J. M. Nunzi, S. Bhattacharyya, S. G. Das, H. Chattopadhyay, EPJ Appl. Phys. 92, (2020)

16. S. Bhattacharyya, H. Chattopadhyay, A. C. Benim, Procedia Engineering, 157, 19 (2016)

17. P. Singh, S. Ekkad, Appl. Therm. Eng., 116, 205 (2017)

18. A. Kumar, M.-H. Kim, Energies, 9, 564 (2016)

19. S. Eiamsa-ard, K. Wongcharee, Int. J. Mech. Sci., 337, 146 (2018)

20. E. J. Onyiriuka, O. O. Ighodaro, A. O. Adelaja, D. R. E. Ewim, S. Bhattacharyya, Heliyon 5, e02416 (2019)

21. M. S. Tahat, A. C. Benim, Defect and Diffusion Forum 374, 148 (2017)

22. R. Karwa, S. C. Solanki, J. S. Saini, Int. J. Heat Mass Transf., 42, 1597 (1999)

23. L. Z. Zhang, Numer. Heat Transf. Part A Appl., 48, 387 (2005)

24. S. W. Chang, Y. R. Jian, Appl. Therm. Eng., 114, 1325 (2017)

25. S. K. Jain, G. Das Agrawal, R. Misra, J. Therm. Sci. Eng. Appl., 12, 1 (2020)

26. S. K. Saha, Exp. Therm. Fluid Sci., 34, 575 (2010)

27. S. Bhattacharyya, H. Chattopadhyay, A. C. Benim, Prog. Comput. Fluid Dyn., 17, 390 (2017) 
28. A. Kumar, R. Maithani, A. R. S. Suri, Heat Mass Transf. Und Stoffuebertragung, 53, 3501 (2017)

29. J. Du, Y. Hong, Int. J. Heat Mass Transf., 154, 119726 (2020)

30. N. Gan Jia Gui, C. Stanley, N. T. Nguyen, G. Rosengarten, Int. J. Heat Mass Transf., 123, 110 (2018)

31. C. Qi, J. Tang, F. Fan, Y. Yan, Appl. Therm. Eng., 179, 115717 (2020)

32. M. H. Aghabozorg, A. Rashidi, S. Mohammadi, Exp. Therm. Fluid Sci., 72, 182 (2016)

33. A. N. Al-Shamani, K. Sopian, H. A. Mohammed, S. Mat, M. H. Ruslan, A. M. Abed, Case Stud. Therm. Eng., 5, 48 (2015)

34. C. Gnanavel, R. Saravanan, M. Chandrasekaran, Mater. Today Proc.. 21, 865 (2020)

35. F. Pourfattah, M. Motamedian, G. Sheikhzadeh, D. Toghraie, O. Ali Akbari, Int. J. Mech. Sci., 131132, 1106 (2017)

36. H. E. Ahmed, B. H. Salman, A. S. Kerbeet, Int. J. Heat Mass Transf., 134, 30 (2019)

37. M. R. Safaei, H. Togun, K. Vafai, S. N. Kazi, A. Badarudin, Numer. Heat Transf. Part A Appl., 66, 1321 (2014)

38. A. S. Navaei, H. A. Mohammed, K. M. Munisamy, H. Yarmand, S. Gharehkhani, Powder Technol., 286, 332 (2015)

39. S. D. Salman, Heat Transf. - Asian Res., 48, 148 (2019)

40. F. R. Menter, T. Esch, S. Kubacki, Eng. Turbul. Model. Exp., 5, 555 (2002)

41. F. M. White, Fluid Mechanics, $7^{\text {th }}$ ed (McGraw Hill, New York, 2011)

42. E. J. Wasp, R. L. Gandhi, J. P. Kenny, Ser. Bulk. Mater. Handl. 1, 4 (1977)

43. H. C. Brinkman, J. Chem. Phys., 20, 571 (1952)

44. B. C. Pak, Y. I. Cho, Exp. Heat Transf., 11, 151 (1998)

45. V. Gnielinski, Int. Chem. Eng., 16, 2 (1976)

46. R. H. Notter, C. A. Sleicher, Chem. Eng. Sci. 27, (1972)

47. R. K. Shah, D. P. Sekulic, Fundamentals of Heat Exchanger Design (Wiley, Hoboken, 2003) 